University of Nebraska - Lincoln

DigitalCommons@University of Nebraska - Lincoln

USDA National Wildlife Research Center - Staff Publications
U.S. Department of Agriculture: Animal and Plant Health Inspection Service

2013

The Effect of Social Hierarchy on Captive Coyote (Canis latrans) Foraging Behavior

Lynne B. Gilbert-Norton

Utah State University, Igilbertnorton@gmail.com

Ryan R. Wilson

Wilderness Society

John A. Shivik

Utah State University

Follow this and additional works at: https://digitalcommons.unl.edu/icwdm_usdanwrc

Gilbert-Norton, Lynne B.; Wilson, Ryan R.; and Shivik, John A., "The Effect of Social Hierarchy on Captive Coyote (Canis latrans) Foraging Behavior" (2013). USDA National Wildlife Research Center - Staff Publications. 1238.

https://digitalcommons.unl.edu/icwdm_usdanwrc/1238

This Article is brought to you for free and open access by the U.S. Department of Agriculture: Animal and Plant Health Inspection Service at DigitalCommons@University of Nebraska - Lincoln. It has been accepted for inclusion in USDA National Wildlife Research Center - Staff Publications by an authorized administrator of DigitalCommons@University of Nebraska - Lincoln. 


\title{
The Effect of Social Hierarchy on Captive Coyote (Canis latrans) Foraging Behavior
}

\author{
Lynne B. Gilbert-Norton*, Ryan R. Wilson† \& John A. Shivik: \\ * Department of Wildland Resources, Utah State University, Logan, UT, USA \\ $\dagger$ The Wilderness Society, Anchorage, AK, USA \\ \$ USDA Wildlife Service's National Wildlife Research Center, Utah State University, Logan, UT, USA
}

\section{Correspondence}

Lynne B. Gilbert-Norton, Department of Wildland Resources, 2810 Old Main Hill, Utah

State University, Logan, UT 84322, USA.

E-mail: Igilbertnorton@gmail.com

Received: August 12, 2012

Initial acceptance: December 3, 2012

Final acceptance: January 26, 2013

(D. Zeh)

doi: $10.1111 /$ eth. 12070

\begin{abstract}
Foraging efficiency of individuals in pack forming species may be influenced by social dynamics within a pack. The effects of social hierarchy in particular may influence individual foraging behavior in canids, such as coyotes (Canis latrans). To examine the impact of social hierarchy on foraging behavior, we tested 16 captive coyotes in eight naturally established dominant-subordinate pairs, using the guesser-knower paradigm. We measured the efficiency of subordinate coyotes to relocate a food resource when alone and then allowed pairs to forage together, such that subordinates had prior knowledge of food location but dominants did not. To determine whether (1) subordinates used a direct or discursive strategy to obtain food in the presence of a dominant and (2) dominants used an exploitative or independent strategy to obtain food in the presence of a subordinate with previous knowledge, we measured their search efficiency (e.g., correct choice of area, feeder, and latency to correct feeder). Results showed subordinates learned to relocate food and increase efficiency when alone. In a social context, however, subordinate efficiency decreased. That is, subordinates approached the correct area, but searched more feeders before finding the correct one. Dominants initially used an independent search strategy but then quickly displaced the subordinate and monopolized the resource, reducing subordinate efficiency further. Despite continual displacement and reduction in efficiency, subordinates did not alter their foraging strategy over time. Our results suggest prior information can improve individual foraging advantage, but that social status strongly impacts individual foraging efficiency in social species such as coyotes.
\end{abstract}

\section{Introduction}

Individuals can improve foraging efficiency by applying previous experience of resource distributions and adapt behavior accordingly. When resources are clumped and relatively stable, an animal should return to the area where food was previously found. When patches are variable and dispersed, an animal should search elsewhere once food is consumed at a particular location (Olton et al. 1981). Foraging strategy models based on resource distributions have been described in various mammal species (Olton $\delta$
Schlosberg 1978; Olton et al. 1981; MacDonald et al. 1994; Laughlin \& Mendl 2000).

In social situations, however, individual foraging strategies can be impacted by conspecifics, particularly within groups that have a hierarchical social structure (Barta \& Giraldeau 1998; Rands et al. 2006). Interference may be positive or negative depending upon the social status of the individual forager. Individuals of high social rank generally have preferential access to food resources (Drews 1993) and can readily exploit resources of subordinates (scrounge: Barnard 8 Sibley 1981). Scrounging can improve foraging efficiency by 
reducing search effort and increasing energetic intake (Clark \& Mangel 1984). In contrast, subordinates may have to alter strategies to counteract social competition, that is, consume as much as possible before being displaced, access resources once dominant individuals have eaten, or forage elsewhere (Rands et al. 2006).

Potential mechanisms that can increase competitive edge for subordinates in a social context are preferentially learning food cues (Hollis et al. 2004) and remembering food locations (Box \& Gibson 1999; Galef \& Laland 2005). Subordinate pigs that learn food locations can subsequently use their knowledge to access food before dominant pigs that are naïve to that location (Held et al. 2000). Dominant pigs invariably displace subordinates and exploit resources; however, subordinates have been shown to alter foraging strategies and counteract such exploitation (Held et al. 2002).

Many canid species forage individually and in groups with hierarchical social systems (Nel 1999). Differential response to resources as a function of social rank has been reported between wolves (Canis lupus) and coyotes (Canis latrans; Atwood \& Gese 2008), and within coyotes (Bekoff \& Wells 1981; Gese et al. 1996). Resource distributions can also affect canid foraging behavior, both in the wild (MacCracken \& Hansen 1987; Hernández et al. 2002) and in captivity (Loether 1978; Cheney 1982; Gilbert-Norton et al. 2009). Despite the effects of both social status and resource distributions on canid behavior (Bekoff \& Wells 1981), to our knowledge, no simultaneous manipulations of foraging context and resource distributions have been conducted with canids.

The aim of our study was to determine (1) how canids improve foraging efficiency when foraging individually and (2) how social status impacts individual foraging efficiency. Coyotes provide an excellent model to explore individual and social foraging strategies in canids because of their well-defined social hierarchy. Social units vary from large packs to individuals, although the typical unit is a territorial breeding pair and respective offspring (Bekoff $\&$ Gese 2003). We used an experimental analog of the guesser-knower paradigm, which was originally used to explore the effect of social hierarchy on foraging behavior in a group of chimpanzees (Pan troglodytes; Menzel 1974). The methodology has since been adapted to explore foraging strategies within dyads, with social status assigned by researchers according to phenotypic traits (Held et al. 2000, 2002, 2010). The guesser-knower method requires a subordinate to learn a spatial food distribution and locate a single food source. They are then paired with a dominant with no previous experience of the distribution. Subordinate pigs increase efficiency when alone by relocating the known location. In pairs, subordinate efficiency is reduced as naïve dominant pigs increase their own efficiency by following and displacing subordinates from the resource (Held et al. 2000).

We extended previous dyad foraging research by using naturally established dominance hierarchies, thereby mirroring natural hierarchies in canid species (Mech 1999; Bekoff \& Gese 2003). In the wild, canids often scent mark food caches (Henry 1977; Harrington $1981 a, b)$ and are able to return to specific areas to hunt or forage (Gese et al. 1996). Therefore, we predicted that individual coyotes would use either olfactory or memory cues to relocate a single food source and increase subsequent foraging efficiency. In a social context, however, we expected social hierarchy to impact individual foraging behavior. We predicted that in the presence of a dominant coyote, a subordinate with food location knowledge would either (1) approach the food and consume as much as possible before being displaced (direct strategy) or (2) forage elsewhere and approach the known location only once the dominant had left (discursive strategy). We predicted that if a subordinate used a direct strategy, then a naïve dominant coyote would follow and displace the subordinate and increase its own efficiency (exploitation strategy). Alternatively, if the subordinate used a discursive strategy, then a naïve dominant coyote would use their own strategy to find food (independent strategy).

\section{Methods}

\section{Subjects}

Sixteen adult captive coyotes (eight male and female breeding pairs) at the National Wildlife Research Center Predator Research Facility in Millville, Utah, were used in this study. Individual coyotes at the Facility usually become breeding pairs when they reach an appropriate reproductive age. Breeding pairs remain together year round, and most pairs successfully produce one litter of pups in the spring of each year. The coyotes were kept in breeding pairs, which improves similarities between captive and wild coyote behavioral budgets (Shivik et al. 2009) and maintains their natural social order. Each pair was housed and tested in one of four adjacent 1-ha wedge-shaped experimental pens that contained natural fallow-field vegetation (grass), shade shelters, and two adjoining kennels under an observation building (Fig. 1). 


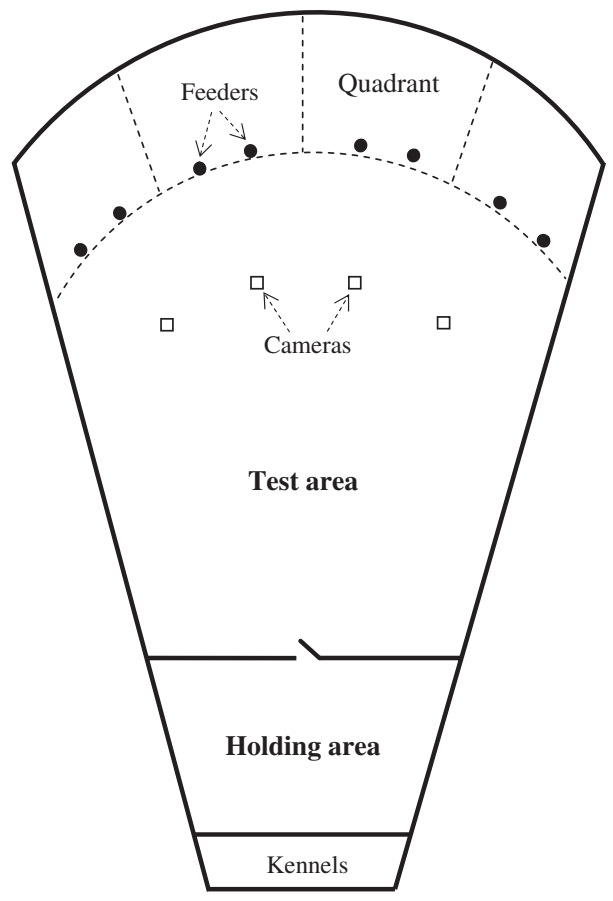

Fig. 1: Division of each 1-ha experimental pen into a holding area and a test area. The test area contained eight feeders placed in four quadrants, and four cameras with one camera observing each quadrant (not to scale).

Coyotes were given four weeks to adjust to their pen before training and testing began. Pairs were trained and tested outside of breeding and pup-rearing seasons to avoid any unnecessary disturbance to the coyote breeding cycle.

We divided each pen into a test area and a holding area using an opaque fence with a guillotine door that facilitated separation of pairs during individual foraging trials. All foraging trials took place in the test area using feeders secured in eight locations along a test arc. The arc was located parallel to the farthest fence line to the holding area (approximately $90 \mathrm{~m}$ from the holding area). The arc was visually divided into four equal sized 'quadrants'. Each quadrant contained two feeders positioned $7 \mathrm{~m}$ apart, and $14 \mathrm{~m}$ from an adjacent pair (Fig. 1). The quadrant design allowed us to identify whether coyotes searched a general area (i.e., the quadrant) or a specific area (i.e., the feeder) once they reached the test arc.

Each feeder was constructed from a $30-\mathrm{cm}$ length of plastic pipe, separated in to two compartments. One compartment was open ended to allow coyotes access to food, and the other compartment was capped and drilled with holes to control for olfactory cues from inaccessible food. Feeders were secured in position along the arc by clipping them to a metal stake buried at each location. The 'correct' feeder contained food in both accessible and inaccessible compartments. Dummy feeders contained inaccessible food only.

\section{Training}

We tested social status within coyote pairs via food dominance, using a single food resource. We tested dominance over four winner-loser trials and recorded the total number of displacements from food (250 g of commercial hotdogs) for each pair member. This method is commonly used for establishing dominance in dyads (Drews 1993) and has previously been used in both coyote (Johnson \& Balph 1990; Mettler \& Shivik 2007) and wolf dyads (Canis lupus; Fox 1972). Displacements were reciprocal such that a win by one animal equaled a loss by the other. We defined the animal that displaced the other coyote from the food more often as the dominant coyote, and the animal that was displaced more often as the subordinate coyote.

After establishing dominance, we trained coyotes over five successive days to search for the correct feeder. On day one, we divided each pairs' daily food ration (i.e., $800 \mathrm{~g}$ of commercial mink food) between eight feeders and allowed both coyotes to search the test arc and consume food from each feeder. On day two, we released coyotes individually from the holding area and then together as a pair to search all eight feeders. Over the next three days, we reduced the number of feeders with accessible food daily, that is, from eight feeders to four, four feeders to two, and then finally from two to one. No behavioral data were recorded during the training phase.

\section{Testing}

We used a repeated measures, within subject design over two phases to explore individual and social foraging strategies. In the first phase, coyotes were tested alone to measure individual foraging efficiency, and in the second phase, coyotes were tested in pairs to explore efficiency in a social context. The first group of four pairs was tested in June and the second group in December 2008. To explore individual foraging strategies, we conducted two trials per day for each subordinate and dominant coyote. Trials were counterbalanced between animals to control for potential order effects. Before daily trials began, both coyotes were placed in the holding area. The experimenter then walked along the test arc to control for human scent cues, and baited one correct feeder and seven dummy feeders. In the first daily trial, a subordinate 
was released and searched for the correct feeder in an array of eight possible locations (individual search condition). The trial ended once the coyote had eaten the food and returned to the holding area (within $6 \mathrm{~min})$. Feeders were then wiped with a mild bleach solution and rebaited. In the second trial, the released subordinate searched for the correct feeder, which was placed in the same location as previously (individual relocation condition). Subordinate feeder locations were randomized without replacement each day. Dominant coyotes were also given two individual trials per day; however, the correct feeder was placed in a different location for each trial (search 1 and search 2), that is, randomized without replacement each trial. Coyotes received $50 \%$ of their daily food ration during trials and 50\% $\mathrm{l} \mathrm{h}$ after trials ended. Non-tested coyotes were given equal amounts of food as the test subject to control for potential differences in food motivation through time.

Individual trials continued until the subordinate from each pair had successfully reached a search criterion. Specifically, the first feeder visited by the subordinate in three consecutive relocation trials (one per day) was the correct feeder (i.e., no investigation errors). An investigation error occurred when a coyote visited a dummy feeder before the correct feeder. If individual subordinates took longer than eight trials to reach the search criterion, we repeated the randomization of feeder location without replacement for a second time. Once the criterion had been reached, the pair proceeded to the social foraging phase.

The social foraging phase consisted of two trials per day with the feeder placed in the same position for both trials. Trials were conducted using the same procedure as previously. In the first trial, a subordinate was released from the holding area and searched alone for the correct feeder (pair search condition). Dominant coyotes were fed equal amounts of food in the holding area to control for potential differences in food motivation between animals during the second trial. In the second trial, dominant and subordinate coyotes were released together to search for the correct feeder (pair condition). Thus, the second trial represented a relocation trial for the subordinate, but a search trial for the dominant. Trials ended after $10 \mathrm{~min}$, which allowed both coyotes time to access the correct feeder regardless of which animal reached the feeder first. Paired trials were repeated eight times so that the correct feeder had been placed in each potential location once.

After trials ended, all coyotes remained within established pairs at the National Wildlife Research
Center Predator Research Facility for future studies. Experiments conducted in this study comply with current US laws on ethical standards for animal use. Research and handling protocols were reviewed and approved by Institutional Animal Care and Use Committees at the National Wildlife Research Center and Utah State University.

\section{Analysis}

We recorded behavior using Noldus Observer $^{\circledR}$ software (Noldus, Leesburg, VA, USA). We recorded the first quadrant entered by a coyote in each trial to determine search accuracy. The 'correct' quadrant contained the accessible feeder. We calculated the mean percent correct for each animal in each condition (number correct / number of trials per condition).

We recorded individual latency to find the correct feeder in each trial in each condition as the time a coyote left the holding area to when it started eating. We also recorded the number of dummy (i.e., investigation errors) and correct feeders searched by each animal in each condition. Our unit of analysis was the individual coyote. To compare subordinate and dominant performance under different conditions, we analyzed within subject behavior using linear mixed effects models, with individual as a random effect using the function 'Ime' in R ( $\mathrm{R}$ Development Core Team 2012). To analyze subordinate and dominant performance within the pair conditions, we also used linear mixed effects models but with pair as a random effect.

To determine if coyotes altered foraging strategies over time, we recorded the latency of subordinate and dominant coyotes to the correct feeder in the first and eighth trials in the pair condition. Additionally, as a measure of foraging success, we compared the time subordinate and dominant coyotes spent eating from the correct feeder in each paired. For both, we tested for differences in the response by social status with linear mixed effects models, using the pair as a random effect.

Finally, to explore whether coyotes used scent marking as a relocation aid, we recorded the frequency of marks (urinations) that subordinates made to the correct and dummy feeders during individual search trials and pair search trials. We compared observed proportions to expected proportions of marking within individual and pair search conditions using chi-square goodness-of-fit tests $\left(\chi_{2}\right)$. Expected frequencies for marks on correct feeders were $1 / 8$ and for incorrect feeders were $7 / 8$. 


\section{Results}

There was considerable variation by individual coyote performance in approaching the correct quadrant, latency to find the correct feeder, and the number of feeders searched across individual and pair conditions (Table 1).

\section{Dominance status}

Dominance varied by gender between the two groups (Table 1). Six males and two females were food dominant, with both dominant females in the second group. The number of displacements by dominants varied between pairs, $(\bar{x}=25.8, \mathrm{SE}=8.5)$.

\section{Individual and pair conditions}

All subordinate coyotes learned to relocate food, but the number of trials to reach the search criterion varied between individuals, $(\bar{x}=7.63, \mathrm{SE}=0.9)$. When foraging alone, subordinates approached the correct quadrant in the relocation condition more than in the search condition ( $\beta=-35.75, p=0.002$, Fig. 2 ) and more in the pair condition than in the pair search condition $(\beta=-31.75, p=0.004)$. One dominant was excluded from analysis because he failed to complete any of the conditions. When foraging alone, dominants did not approach the correct quadrant

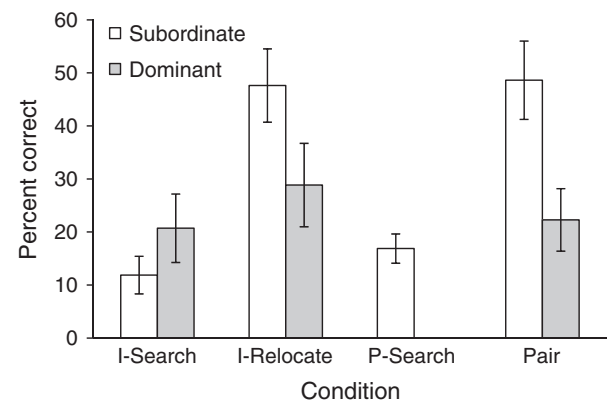

Fig. 2: Mean percentage (and SE) of approaches to the correct quadrant by subordinate and dominant coyotes in individual conditions (ISearch and I-Relocate), and pair conditions (P-Search; subordinates only, and Pair).

significantly more in search 2 versus search 1 condition $(\beta=-8.14, p=n s)$ or in the pair compared with the individual search two condition $(\beta=-6.57$, $\mathrm{p}=\mathrm{ns}$ ). In the pair trial, subordinates approached the correct quadrant more frequently than dominant coyotes $(\beta=26.36, p=0.037)$.

There was no difference in latency to find the correct feeder by subordinates in individual search and relocation conditions $(\beta=0.045, p=n s)$ or in the pair and pair search conditions $(\beta=1.101, p=n s$, Fig. 3). There was no difference in latency for dominants in individual search 2 and search 1 conditions, $(\beta=0.20, p=n s)$, or in the pair and individual search conditions $(\beta=-0.391, p=n s)$. Subordinates were

Table 1: The percentage of correct quadrants approached, latency to the correct feeder (seconds) and average number of feeders searched before and including the correct feeder by each coyote in the individual search (I-Search), individual relocate (I-Relocate), pair search (P-Search; subordinates only) and pair conditions. $S$ = subordinate; $D=$ dominant for each breeding pair of coyotes ( $n=16$ coyotes; 8 pairs)

\begin{tabular}{|c|c|c|c|c|c|c|c|c|c|c|c|c|c|}
\hline \multicolumn{2}{|c|}{ Tested June 2008} & \multicolumn{4}{|c|}{ Latency to correct feeder (s) } & \multicolumn{4}{|c|}{ Correct quadrant (\%) } & \multicolumn{4}{|c|}{ Average feeders searched } \\
\hline Status & Gender/Pair & I-Search & I-Relocate & P-Search & Pair & I-Search & I-Relocate & P-Search & Pair & I-Search & I-Relocate & P-Search & Pair \\
\hline S & Female 1 & 40 & 48 & 39 & 318 & 20 & 42 & 20 & 25 & 4.5 & 2.4 & 4.3 & 9.9 \\
\hline D & Male 1 & 43 & 56 & - & 30 & 0 & 14 & - & 25 & 3.6 & 3.1 & - & 3.4 \\
\hline $\mathrm{s}$ & Female 2 & 39 & 42 & 47 & 18 & 0 & 33 & 13 & 75 & 3.8 & 1.3 & 5.0 & 1.1 \\
\hline D & Male 2 & 64 & 126 & - & 18 & - & - & - & - & 3.6 & 4.6 & - & 1.5 \\
\hline $\mathrm{s}$ & Female 3 & 33 & 30 & 31 & 30 & 0 & 60 & 33 & 60 & 3.2 & 1.6 & 3.2 & 1.4 \\
\hline D & Male 3 & 46 & 65 & - & 385 & 20 & 20 & - & 27 & 3.8 & 3.8 & - & 9.6 \\
\hline $\mathrm{s}$ & Female 4 & 54 & 26 & 33 & 124 & 0 & 50 & 19 & 44 & 3.6 & 1.6 & 3.3 & 4.2 \\
\hline D & Male 4 & 36 & 48 & - & 23 & 25 & 25 & - & 19 & 3.8 & 4.9 & - & 3.8 \\
\hline \multicolumn{2}{|c|}{ Tested Dec 2008} & I-Search & I-Relocate & P-Search & Pair & I-Search & I-Relocate & P-Search & Pair & I-Search & I-Relocate & P-Search & Pair \\
\hline S & Female 5 & 40 & 25 & 36 & 16 & 20 & 50 & 20 & 82 & 3.8 & 1.9 & 2.6 & 1.2 \\
\hline D & Male 5 & 70 & 51 & - & 18 & 17 & 33 & - & 55 & 4.5 & 3.5 & - & 1.3 \\
\hline S & Male 6 & 37 & 49 & 38 & 35 & 13 & 13 & 13 & 25 & 2.4 & 1.9 & 1.6 & 1.2 \\
\hline D & Female 6 & 54 & 51 & - & 34 & 50 & 0 & - & 13 & 2.8 & 3.0 & - & 2.4 \\
\hline S & Female 7 & 27 & 23 & 34 & 164 & 25 & 50 & 9 & 36 & 3.0 & 1.0 & 2.2 & 2.3 \\
\hline D & Male 7 & 56 & 66 & - & 62 & 0 & 43 & - & 9 & 2.9 & 2.0 & - & 1.4 \\
\hline S & Male 8 & 31 & 22 & 30 & 64 & 17 & 83 & 8 & 42 & 3.2 & 1.2 & 3.3 & 2.8 \\
\hline D & Female 8 & 39 & 25 & - & 71 & 33 & 67 & - & 8 & 3.7 & 1.8 & - & 3.8 \\
\hline
\end{tabular}




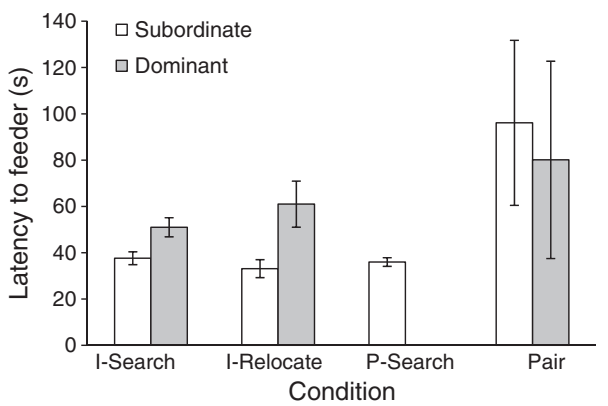

Fig. 3: Mean latency in seconds (and SE) to find the correct feeder by subordinate and dominant coyotes in individual conditions (I-Search and I-Relocate), and pair conditions (P-Search; subordinates only, and Pair).

faster than dominants at locating the correct feeder in individual search conditions $(\beta=-0.234, p=0.047)$ and faster in their individual relocation condition than dominants were in their individual search 2 condition $(\beta=-0.479, \mathrm{p}=0.038)$. In the pair trial, there was no difference in latency to find the correct feeder by status $(\beta=0.260, \mathrm{p}=\mathrm{ns})$.

Subordinates investigated more feeders during individual search compared with individual relocation conditions $(\beta=1.833, p<0.001)$, but there was no difference in the number of feeders subordinates investigated in the pair condition compared with the individual relocation condition $(\beta=-1.400, p=n s$, Fig. 4). There was no difference in the number of feeders investigated by dominant coyotes in individual search 1 and search 2 conditions $(\beta=-0.241$, $\mathrm{p}=\mathrm{ns})$ or in individual search 2 and pair conditions ( $\beta=-0.039, p=n s)$. In the pair condition, there was no difference in the number of feeders investigated by subordinates compared with dominant coyotes, $(\beta=-0.370, p=n s)$.

There was no change in latency to the correct feeder across the pair condition by either subordinate (mean rank $=6.93$ ) or dominant coyotes $($ mean rank $=8.07$ )

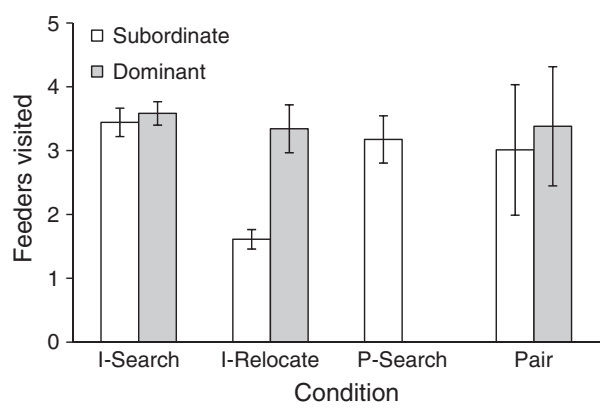

Fig. 4: Mean number of feeders (and SE) searched (before and including the correct feeder) by subordinate and dominant coyotes in individual conditions (I-Search and I-Relocate), and pair conditions (P-Search; subordinates only, and Pair). when we compared the first and eighth trials (subordinate: $\beta=0.273, p=n s$; dominant: $\beta=-0.071, p=n s$ ). In the pair condition, subordinates spent less time eating from the correct feeder $(\bar{x}=18.4, \mathrm{SE}=6.1)$ than dominants $(\bar{x}=41.8, \mathrm{SE}=4.2 ; \beta=-23.329, \mathrm{p}=0.019)$.

Subordinate coyotes marked the correct feeder (count $=83$ ) more often than dummy feeders (count $=79)$ when compared with expected frequencies $(1 / 8$ feeders $=$ correct, $7 / 8=$ dummy) in the individual search condition $\left(\chi_{2}^{2}=222.21, \mathrm{p}<0.0001\right)$. Subordinates also marked the correct feeder $($ count $=79)$ more than dummy feeders $($ count $=53)$ when compared with expected frequencies in the pair search condition $\left(\chi_{2}^{2}=270.56, \mathrm{p}<0.0001\right)$.

\section{Discussion}

When alone, subordinate coyotes increased foraging efficiency by relocating the same resource with minimal location errors. In a social foraging context, however, subordinate efficiency decreased. That is, subordinate coyotes likely knew the correct food location in paired trials because they approached the correct quadrant, but searched more dummy feeders before the correct feeder. Once at the correct feeder, subordinates were quickly displaced by the dominant animal, which monopolized the resource. Consequently, subordinate coyotes lost energetically to dominant individuals despite pre-existing location knowledge, which suggests social dynamics overrides information use in social canids like coyotes.

Overall, latencies to find the correct feeder were similar for dominant and subordinate coyotes in individual search trials. However, individual subordinate coyotes searched fewer feeders and relocated the correct feeder more quickly than individual dominant coyotes in their second daily trial. Results suggest that subordinates used location knowledge gained during the first trial to reduce relocation errors in the second trial. Dominant coyotes were unable to use such information as the location of their feeder changed between successive trials.

In a social context, we found subordinate coyotes used a direct strategy to approach the correct quadrant. That is, although subordinates had the opportunity to follow an animal of higher social status and forage in a pair, they invariably left the holding area first, chose their own route to the feeders and foraged independently throughout the pair trial. One explanation for the direct approach used by subordinates is that they would be unaware of the information dominants had regarding resource distributions. Animals of lower social status often use producing strategies in 
competitive foraging contexts (Held et al. 2002; Lendvai et al. 2006). Responding quickly to potential resources may increase competitive advantage for subordinate individuals in hierarchical social groups where dominants monopolize resources. Johnson \& Balph (1990) showed subordinate coyotes are faster to access resources under novel conditions in which dominants are more reticent. Similarly, smaller, subordinate pigs increase foraging speed against dominant pigs to gain resources first in social foraging contexts (Held et al. 2010).

Although subordinates implemented a direct strategy to approach the correct area, they often searched dummy feeders before the correct one, which suggests a reduction in relocation accuracy when paired with dominant coyotes. Hence, there was no difference in time to reach the correct feeder by subordinate or dominant coyotes in paired trials. Pigs make relocation errors when subjected to mild environmental disturbance (Mendl et al. 1997), and disturbance can be socially mediated, that is, from the presence of conspecifics (Rands et al. 2006). Bekoff (1978) suggested the mere presence of dominant coyotes was sufficient to have a controlling effect on the behavior of subordinates. Thus, the observed reduction in accuracy by subordinate coyotes is likely a function of perceived or real competitive threat from the dominant individual.

Dominant coyotes did not follow subordinates from the holding area, thus used an independent search strategy throughout trials. However, dominant coyotes immediately took possession and monopolized the resource once the subordinate was seen at the food location. In social situations, dominant animals can reap greater net rewards by following, stealing, or scrounging food from conspecifics (Barta $\&$ Giraldeau 1998; Giraldeau \& Caraco 2000; Held et al. 2000). Our results suggest that foraging 'success' in coyotes may not be a function of which animal is first to a resource, but which animal is able to monopolize resources and gain energetic input.

Interestingly, although subordinates were repeatedly and aggressively displaced, they failed to adjust their strategy over time to counteract loss of resources. That is, subordinates continued to use a direct strategy to access the resource first and attempted to defend their find from dominants throughout trials, but invariably failed. Once displaced, subordinates either remained close by, or investigated other feeders. Only when the dominant coyote left the feeder would the subordinate reapproach the feeder to investigate what was left. Social hierarchy is fundamental in providing a framework for interactions between coyote pack members (Bekoff \& Gese 2003). Individuals appear to readily accept their status within a pack and the constraints imposed on resources by that social position. However, given that coyotes have been observed altering strategies according to either familiar or novel foraging conditions (Johnson \& Balph 1990), it would be interesting to determine if dominant or subordinate coyotes would learn to alter foraging strategies over the long term to counteract social constraints.

Subordinate coyotes marked correct feeders more often than expected, which suggests coyotes use scent cues to increase foraging efficiency. However, two coyotes did not mark feeders yet still successfully relocated food, which suggests they also use memory to relocate food resources. Approximately 93 percent of scent-marks were made to the correct feeder once it was empty, as coyotes revisited the feeder during the same trial. Animals may search empty food sites to sample, that is, gather information about resource distributions (Bednekoff \& Balda 1997). Furthermore, tracking changes in resource distributions and continually updating information could increase foraging adaptability in fluctuating environments (Bednekoff \& Balda 1997). Thus, marking may provide coyotes with useful information about the state of resources during future forays.

Our results show that coyotes can remember food locations and minimize visits to locations without food. Such results corroborate studies that show coyotes can track variability in resources to increase foraging efficiency (Gilbert-Norton et al. 2009). The better informed an animal is about its environment, the more adaptable its foraging behavior can be (Clark \& Mangel 1984; Dall et al. 2005). Coyotes are arguably one of the most adaptable canid species in North America, readily exploiting new habitats and resources. However, any advantage in individual adaptability is likely constrained by social hierarchy, and future studies must take in to account the effects of dominance when studying foraging efficiency or strategies in social canid species.

\section{Acknowledgements}

We thank Stacey Brummer, Mike Davis, Jeff Shultz, Patrick Darrow, Caroline David, and Anthony Lot at the National Wildlife Research Center's Predator Ecology Facility in Millville, Utah. We thank the Associate Editor, David Zeh, and an anonymous reviewer for editorial comments and statistical advice that improved the manuscript considerably. We gratefully acknowledge the financial and technical support provided by the USDA, Wildlife Service's National Wildlife Research Center. 


\section{Literature Cited}

Atwood, T. C. \& Gese, E. M. 2008: Coyotes and recolonizing wolves: social rank mediates risk-conditional behaviour at ungulate carcasses. Anim. Behav. 75, 753-762.

Barnard, C. J. \& Sibley, R. M. 1981: Producers and scroungers: a general model and its application to captive flocks of house sparrows. Anim. Behav. 29, 543550.

Barta, Z. \& Giraldeau, L.-A. 1998: The effect of dominance hierarchy on the use of alternative foraging tactics: a phenotype-limited producer-scrounger game. Behav. Ecol. Sociobiol. 42, 217-223.

Bednekoff, P. A. \& Balda, R. P. 1997: Clark's nutcracker spatial memory: many errors might not be due to forgetting. Anim. Behav. 54, 691-698.

Bekoff, M. 1978: Behavioral development in coyotes and Eastern coyotes. In: Coyotes. Biology, Behavior, and Management (Bekoff, M., ed). Academic Press, New York, pp. 97-124.

Bekoff, M. \& Gese, E. M. 2003: Coyote (Canis latrans). In Wild Mammals of North America: Biology, Management and Conservation, 2nd edn. (Feldhammer, G. A., Thompson, B. C., Chapman, J. A., eds). John Hopkins University Press, Baltimore, pp. 467-481.

Bekoff, M. \& Wells, M. C. 1981: Behavioural budgeting by wild coyotes: the influence of food resources and social organization. Anim. Behav. 29, 794-801.

Box, H. O. \& Gibson, K. R. 1999: Social learning and behavioral strategies among mammals. In: Mammalian Social Learning. Comparative and Ecological Perspectives (Box, H. O. \& Gibson, K. R. eds). Cambridge University Press, Cambridge, pp. 401-413.

Cheney, C. D. 1982: Probability learning in captive wolves. In: Wolves of the World. Perspectives of Behavior, Ecology, and Conservation (Harrington, F. H. \& Paquet, P. C. eds). Noyes Publications, New Jersey, pp. 272-281.

Clark, C. W. \& Mangel, M. 1984: Foraging and flocking strategies: information in an uncertain environment. Am. Nat. 123, 626-641.

Dall, S. R. X., Giraldeau, L.-A. A., Olsson, O., McNamara, J. M. \& Stephens, D. W. 2005: Information and its use by animals in evolutionary ecology. Trends Ecol. Evol. 20, 187-193.

Drews, C. 1993: The concept and definition of dominance in animal behaviour. Behaviour 125, 283-313.

Fox, M. W. 1972: Socio-ecological implications of individual differences in wolf litters: a developmental and evolutionary perspective. Behaviour 41, 298-313.

Galef, B. G. Jr \& Laland, K. N. 2005: Social learning in animals: empirical studies and theoretical models. Bioscience 55, 489-499.

Gese, E. M., Ruff, R. L. \& Crabtree, R. L. 1996: Foraging ecology of coyotes (Canis latrans): the influence of extrinsic factors and a dominance hierarchy. Can. J.

Zool. 74, 769-783.

Gilbert-Norton, L. B., Shahan, T. A. \& Shivik, J. A. 2009: Coyotes (Canis latrans) and the matching law. Behav. Process. 82, 178-183.

Giraldeau, L.-A. \& Caraco, T. 2000: Social Foraging Theory. Princeton University Press, New Jersey.

Harrington, F. H. 1981a: Urine marking at food and caches in captive coyotes. Can. J. Zool. 60, 776-782.

Harrington, F. H. 1981b: Urine marking and caching behavior in the wolf. Behaviour 76, 280-288.

Held, S., Mendl, M., Devereux, C. \& Byrne, R. W. 2000: Social tactics of pigs in a competitive foraging task: the 'informed forager' paradigm. Anim. Behav. 59, $569-576$.

Held, S., Mendl, M., Devereux, C. \& Byrne, R. W. 2002: Foraging pigs alter their behaviour in response to exploitation. Anim. Behav. 64, 157-166.

Held, S., Byrne, R. W., Jones, S., Murphy, E., Friel, M. \& Mendl, M. 2010: Domestic pigs, Sus scrofa, adjust their foraging behaviour to whom they are foraging with. Anim. Behav. 79, 857-862.

Henry, J. D. 1977: The use of urine marking in the scavenging behavior of the red fox (Vulpes vulpes). Behaviour 61, 82-106.

Hernández, L., Parmenter, R. R., Dewitt, J. W., Lightfoot, D. C. \& Laundré, J. W. 2002: Coyote diets in the Chihuahuan Desert, more evidence for optimal foraging. J. Arid Environ. 51, 613-624.

Hollis, K. L., Blouin, L. A., Romano, M. C., LangworthyLam, K. S. \& Siegenthaler, J. 2004: Maintaining a competitive edge: dominance hierarchies, food competition and strategies to secure food in green anoles (Anolis carolinensis) and firemouth cichlids (Thorichthys meeki). Int. J Comp. Psychol. 17, 222-240.

Johnson, W. E. \& Balph, D. 1990: Resource acquisition in the presence of novelty by coyotes of different rank. J Wildl. Manage. 54, 582-586.

Laughlin, K. \& Mendl, M. 2000: Pigs shift too: foraging strategies and spatial memory in the domestic pig. Anim. Behav. 60, 403-410.

Lendvai, Á. Z., Liker, A. \& Barta, Z. 2006: The effects of energy reserves and dominance on the use of socialforaging strategies in the house sparrow. Anim. Behav. 72, 747-752.

Loether, R. 1978: An Analysis of the Foraging Strategy of Three Species of Wild Canidae. Thesis, Utah State University, Logan, Utah, M. S.

MacCracken, J. G. \& Hansen, R. M. 1987: Coyote feeding strategies in southeastern Idaho: optimal foraging by an opportunistic predator?. J. Wildl. Manage. 51, $278-285$.

MacDonald, S. E., Pang, J. C. \& Gibeault, S. 1994: Marmoset (Callithrix jacchus jacchus) spatial memory in a 
foraging task: win-stay versus win-shift strategies.

J. Comp. Psychol. 108, 328-334.

Mech, L. D. 1999: Alpha status, dominance, and division of labor in wolf packs. Can. J. Zool. 77, 1196-1203.

Mendl, M., Laughlin, K. \& Hitchcock, D. 1997: Pigs in space: spatial memory and its susceptibility to interference. Anim. Behav. 54, 1491-1508.

Menzel, E. W. J. 1974: A group of young chimpanzees in a one-acre field. In Behavior of Non-human Primates. (Schier, A. M., Stollnitz, F., eds). Academic Press, New York, pp. 83-153.

Mettler, A. E. \& Shivik, J. A. 2007: Dominance and neophobia in coyote (Canis latrans) breeding pairs. Appl. Anim. Behav. Sci. 102, 85-94.

Nel, J. A. J. 1999: Social learning in canids: an ecological perspective. In: Mammalian Social Learning. Comparative and Ecological Perspectives (Box, H. O. \& Gibson, K. R. eds). Cambridge University Press, Cambridge, pp. $259-277$.
Olton, D. S. \& Schlosberg, P. 1978: Food-searching strategies of young rats: win-shift predominates over winstay. J Comp. Physiol. Psychol. 92, 609-618.

Olton, D. S., Handelmann, G. E. \& Walker, J. A. 1981: Spatial memory and food searching strategies. In Foraging Behavior: Ecological, Ethological, and Psychological Approaches. (Kamil, A. C., Sargent, T. D., eds). Garland STPM Press, New York, pp. 333-354.

R Development Core Team 2012: R: A Language and Environment for Statistical Computing. - R Foundation for Statistical Computing, Vienna, Austria.

Rands, S. A., Pettifor, R. A., Rowcliffe, J. M. \& Cowlishaw, G. 2006: Social foraging and dominance relationships: the effects of socially mediated interference. Behav. Ecol. Sociobiol. 60, 572-581.

Shivik, J. A., Palmer, G. L., Gese, E. M. \& Osthaus, B. 2009: Behavioural budgets of captive versus wild coyotes: does environmental enrichment help? J. Appl. Anim. Welfare Sci. 12, 223-235. 